\title{
Desempenho de cabras em lactação alimentadas com dietas com diferentes níveis de fibra oriundas de forragem com maturidade avançada ${ }^{1}$
}

\section{Renata Helena Branco ${ }^{2}$, Marcelo Teixeira Rodrigues ${ }^{3}$, Márcia Maria Cândido da Silva ${ }^{4}$, Carla Aparecida Florentino Rodrigues ${ }^{5}$, Augusto César de Queiroz ${ }^{3}$, Fabiana Lana de Araújo ${ }^{6}$}

\author{
1 Apoio Fapemig. \\ 2 Instituto de Zootecnia - CAPTA Bovinos de Corte. \\ 3 Departamento de Zootecnia - Universidade Federal de Viçosa. \\ ${ }^{4}$ Bolsista PNPD - Capes. Departamento de Zootecnia - UFV. \\ 5 Deparamento de Zootecnia, Faculdade de Veterinária - Universidade Federal Fluminense, Niterói - RJ. \\ ${ }^{6}$ Doutoranda em Zootecnia - Universidade Federal de Viçosa.
}

RESUMO - Objetivou-se com este trabalho avaliar o efeito de diferentes teores de fibra em detergente neutro oriunda da forragem com maturidade avançada sobre o consumo, a digestibilidade da matéria seca e de nutrientes, o balanço de nitrogênio, a produção de leite, a eficiência de utilização da energia metabolizável e o comportamento ingestivo de cabras em lactação. Foram distribuídas cinco cabras em delineamento em quadrado latino $5 \times 5$ utilizando-se teores crescentes de fibra em detergente neutro oriunda da forragem como variável independente. As concentrações de fibra em detergente neutro oriunda da foragem utilizadas foram 20, 28, 35, 43 e 49\%. Os consumos de matéria seca, de nutrientes e de energia líquida reduziram com o aumento de fibra na ração. No entanto, o consumo de fibra em detergente foi crescente, indicando capacidade de acomodação desse componente nutritivo pelos animais. O teor de fibra influenciou os coeficientes de digestibilidade da matéria seca, matéria orgânica, proteína bruta e dos carboidratos não-fibrosos, contudo, a digestibilidade da fibra em detergente neutro não foi influenciada pelas dietas. O nível de fibra em detergente neutro oriunda da forragem não influenciou os constituintes do leite (gordura, proteína e lactose). O teor de fibra oriunda da forragem teve efeito quadrático sobre a produção de leite (corrigida e não corrigida para $4 \%$ de gordura), em kg/dia, com maiores produções obtidas com o teor de $28 \%$ de fibra. A eficiência de utilização da energia metabolizável não foi influenciada pelas variações nas dietas. O teor de fibra em detergente neutro oriunda da forragem influencia o comportamento ingestivo de cabras em lactação, aumentando os tempos de ruminação e mastigação e diminuindo o tempo em ócio dos animais.

Palavras-chave: caprinos leiteiros, comportamento ingestivo, ingestão, produção de leite, ruminação

\section{Performance of lactating goats fed diets containing different fiber levels from forage with advanced maturity}

\footnotetext{
ABSTRACT - The objective of this study was to evaluate the different contents of neutral detergent fiber from forage at advanced maturity on intake, digestibility of the dry matter and of nutrients, nitrogen balance, milk production, efficiency metabolizable energy use and the ingestive behavior of lactating goats. Five dairy goats were distributed in $5 \times 5$ Latin square by using increasing contents of neutral detergent fiber from forage as independent variable. Concentrations of neutral detergent fiber from forage used were 20, 28, 35, 43 and 49\%. The intakes of dry matter, of nutrients and of net energy were reduced with the increase of fiber to the ration. However the intake of neutral detergent fiber was increasing, indicating the capacity of accommodation of this nutrient by the animals. Fiber content influenced digestibility coefficients of dry matter, organic matter, crude protein and non-fibrous carbohydrates but digestibility of neutral detergent fiber was not influenced by the diets. Level of neutral detergent fiber from forage did not influence milk constituents (fat, protein and lactose). Content of fiber from the forage had a quadratic effect on milk production (corrected and not corrected for $4 \%$ of fat) in $\mathrm{kg} . d a y^{-1}$, with greater productions obtained with the content of $28 \%$ of fiber Efficiency of use of the metabolizable energy was not influenced by the variations of the diets. Content of neutra detergent fiber from forage influences ingestive behavior of goats in lactation, increasing the time of rumination and chewing and reducing iddle time of the animals.
}

Key Words: dairy goats, ingestion, ingestive behavior, milk production, rumination

Recebido em 24/9/2009 e aprovado em 29/4/2010. 


\section{Introdução}

Entre as diversas linhas de pesquisa relacionadas à nutrição de animais ruminantes, o estudo da fibra na formulação de rações é de grande importância. A fibra contém a fração de carboidratos dos alimentos de digestão lenta ou indigerível e impõe limitações sobre o consumo de matéria seca e energia. Por outro lado, a saúde dos ruminantes depende diretamente de concentrações mínimas de fibra na ração que permitam manter a atividade de mastigação e a motilidade do rúmen (Nussio et al., 2000).

A formulação de dietas baseadas em fibra em detergente neutro (FDN) tem sido recomendada em razão das relações positiva entre a fibra e a repleção ruminal e negativa entre a densidade energética do alimento (Mertens, 1994). Para manter a função ruminal estável e evitar depressão no teor de gordura do leite, o NRC (2001) recomenda o mínimo de $25 \%$ de fibra na dieta, medida como fibra em detergente neutro, com $75 \%$ do total da dieta sendo suprida por forrageiras.

Para cabras leiteiras, os valores máximo e mínimo de fibra na dieta para maximizar o consumo e a eficiência de produção ainda não estão bem definidos. Carvalho et al. (2006) observaram que $27 \%$ de FDN oriunda da forragem de boa qualidade, otimizou o consumo de matéria seca e a produção de leite corrigido para 3,5\% de gordura. Porém, quando se trabalha com forrageiras com alta concentração de fibras, não se tem dados na literatura, quanto à utilização de forragens com maturidade avançada e ao desempenho de cabras em lactação.

A eficiência de ruminação é também importante no controle da utilização de alimentos de baixa digestibilidade. Neste caso, o animal pode ruminar maiores quantidades de alimentos por tempo de ruminação, aumentando o consumo e melhorando o desempenho produtivo (Welch, 1982). Em dietas com alto conteúdo de FDN, a eficiência de ruminação e mastigação é diminuída, devido à maior dificuldade em diminuir o tamanho das partículas oriundas de materiais ricos em fibra, reduzindo com isso, a ingestão de alimentos (Dulphy et al., 1980).

Portanto, objetivou-se avaliar o efeito da utilização de fibra em detergente neutro oriunda de forragem com maturidade avançada sobre o consumo, a digestibilidade dos nutrientes e o desempenho de cabras leiteiras em lactação.

\section{Material e Métodos}

O ensaio experimental foi realizado nas dependências do setor de Caprinocultura do Departamento de Zootecnia da Universidade Federal de Viçosa utilizando-se cinco cabras, primíparas e multíparas, com aproximadamente 60 dias de lactação e peso corporal médio de 59,13 £ 12,93kg, confinadas em baias individuais.

Os animais foram arranjados em delineamento experimental em quadrado latino $5 \times 5$, para avaliar os efeitos da fibra em detergente neutro oriunda de forragem (FDNf) com maturidade avançada. A base forrageira foi o feno de capim-tifton-85 (Cynodon spp). Os teores de FDNf, 20, 28, 35, 43 e 49\%, foram as variáveis utilizadas para caracterizar as dietas.

Nas formulações das dietas rações o milho (Zea mays L.) constituiu a principal fonte energética e o farelo de soja (Glicine max L.) a fonte proteica, complementados com uma mistura mineral balanceada para atender as exigências nutricionais de cabras leiteiras em lactação, de acordo com as recomendações do AFRC (1993). As rações foram formuladas para serem isoproteicas, com $17 \%$ de proteína bruta na matéria seca (Tabelas 1 e 2). A proporção entre o volumoso e o concentrado variou de acordo com o tratamento, de maneira a se atingir a concentração de FDNf pretendido para as dietas experimentais, as rações foram fornecidas duas vezes ao dia, às 8 e às $16 \mathrm{~h}$.

Cada período experimental teve duração de 21 dias, sendo 14 de adaptação e ajuste do consumo voluntário e sete dias de coleta de dados. Para avaliação do efeito dos tratamentos foram observadas as seguintes variáveis: consumo voluntário; digestibilidade aparente da matéria seca e dos nutrientes; produção de leite e constituintes lácteos; comportamento ingestivo.

Com acesso ad libitum às rações, o consumo voluntário foi calculado pela diferença entre o oferecido e as sobras; para tanto, as sobras foram coletadas diariamente, pesadas e amostradas em $10 \%$ do seu peso, durante os sete dias do período de coleta, sendo ajustadas para corresponderem a 10\% do total oferecido. Para cada animal, constituíram-se amostras compostas de sobras, referentes a cada período experimental, as quais foram congeladas para análises posteriores.

A produção e a composição do leite foram estimadas com base em duas ordenhas diárias e em quatro coletas durante o período experimental: ordenha da tarde do primeiro dia; ordenha da manhã do segundo dia; ordenha da tarde do sexto dia; e ordenha da manhã do sétimo dia. Nas amostras foram determinados os teores de proteína bruta, lactose e gordura. As análises quantitativas do leite foram realizadas no Laboratório de Qualidade do Leite da Empresa Brasileira de Pesquisa Agropecuária (Embrapa Gado de Leite). 
Tabela 1 - Composição dos ingredientes das dietas experimentais

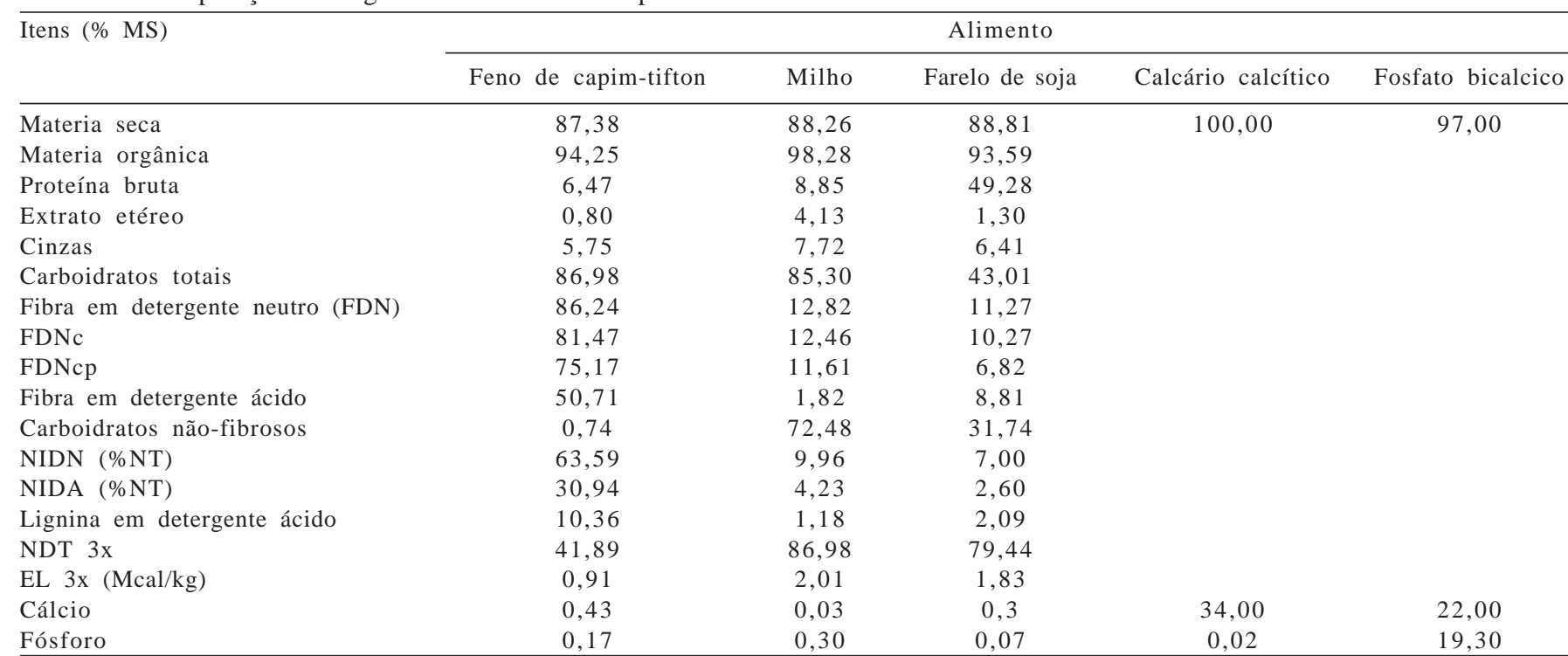

FDNc = fibra em detergente neutro corrigida para cinzas; FDNcp = fibra em detergente neutro corrigida para cinzas e proteína; NIDN = nitrogênio insolúvel em detergente neutro; NIDA = nitrogênio insolúvel em detergente ácido; NDT3x = nutrientes digestíveis totais 3 x mantença; EL3x = energia líquida $3 \mathrm{x}$ mantença.

Tabela 2 - Composição das dietas experimentais, expressa com base na matéria seca

\begin{tabular}{|c|c|c|c|c|c|}
\hline \multirow[t]{2}{*}{ Alimento } & \multicolumn{5}{|c|}{ Nível de FDNf } \\
\hline & 20 & 28 & 35 & 43 & 49 \\
\hline Feno de capim-tifton-85 & 22,53 & 31,55 & 40,56 & 49,57 & 56,33 \\
\hline Farelo de soja & 24,13 & 24,38 & 24,63 & 24,88 & 25,07 \\
\hline Fosfato bicálcico & 1,01 & 1,01 & 1,01 & 1,01 & 1,01 \\
\hline Calcáreo calcítico & 0,51 & 0,51 & 0,51 & 0,51 & 0,51 \\
\hline Materia seca & 88,44 & 88,37 & 88,29 & 88,21 & 88,15 \\
\hline Materia orgânica & 96,28 & 95,91 & 95,53 & 95,16 & 94,88 \\
\hline Proteína bruta & 17,85 & 17,73 & 17,62 & 17,51 & 17,42 \\
\hline Extrato etéreo & 2,59 & 2,29 & 1,98 & 1,67 & 1,44 \\
\hline Cinzas & 3,72 & 4,09 & 4,47 & 4,84 & 5,12 \\
\hline Carboidratos totais & 73,33 & 73,37 & 73,42 & 73,47 & 73,50 \\
\hline NIDA (\%NT) & 9,75 & 12,15 & 14,56 & 16,96 & 18,76 \\
\hline Lignina em detergente ácido & 3,44 & 4,27 & 5,10 & 5,93 & 6,55 \\
\hline NDT $3 x$ & 72,81 & 68,73 & 64,65 & 60,56 & 57,50 \\
\hline EL 3x (Mcal/kg) & 1,67 & 1,57 & 1,47 & 1,37 & 1,29 \\
\hline Cálcio & 0,64 & 0,68 & 0,71 & 0,75 & 0,78 \\
\hline Fósforo & 0,31 & 0,29 & 0,28 & 0,27 & 0,26 \\
\hline FDNf & 19,43 & 27,21 & 34,98 & 42,75 & 48,58 \\
\hline
\end{tabular}

${ }^{1}$ Mistura mineral: 0,32\% de sulfato ferroso; $0,48 \%$ de sulfato de cobre; 0,71\% de sulfato de manganês; $2,67 \%$ de sulfato de zinco; $0,02 \%$ de sulfato de cobalto; iodato de potássio - 0,0125\%; cloreto de sódio - 95,78\%.

NIDN = nitrogênio insolúvel em detergente neutro; NIDA = nitrogênio insolúvel em detergente ácido; NDT3x = nutrientes digestíveis totais 3x mantença; EL3x = energia líquida $3 \mathrm{x}$ mantença; FDNf = fibra em detergente neutro oriunda da forragem.

Durante os dias um a cinco do período de coleta de dados, foram efetuadas coletas totais de fezes e urina para determinação da digestibilidade aparente e do balanço de nitrogênio, respectivamente. A urina foi coletada em recipientes plásticos contendo $20 \mathrm{~mL}$ de solução de $\mathrm{H}_{2} \mathrm{SO}_{4}$
$40 \%(\mathrm{v} / \mathrm{v})$. Fezes e urina, depois de coletadas e pesadas, foram amostradas em alíquotas de $10 \%$ e congeladas para posteriores análises laboratoriais.

Nos alimentos, determinou-se a composição em matéria seca e nitrogênio total para estimativa da proteína bruta; 
extrato etéreo, cinzas utilizando as técnicas descritas em Silva e Queiroz (2002); fibra em detergente neutro e fibra em detergente ácido, lignina em detergente ácido segundo Van Soest et al. (1991); nitrogênio insolúvel em detergente neutro, nitrogênio insolúvel em detergente ácido segundo técnicas descritas por Licitra et al. (1996). As sobras e as fezes foram analisadas para determinação do conteúdo de matéria seca, proteína bruta, extrato etéreo, cinzas, fibra em detergente neutro, fibra em detergente ácido e lignina em detergente ácido.

As concentrações em carboidratos não-fibrosos foram obtidos a partir da equação: $\mathrm{CNF}=100-(\% \mathrm{~PB}+\% \mathrm{EE}+\% \mathrm{CZ}$ + \%FDN), segundo Van Soest et al. (1991).

O valor de nutrientes digestíveis totais para mantença foi estimado segundo o NRC (2001). Para a quantificação do valor de energia das dietas, aplicou-se os dados da digestibilidade aparente, utilizando a equação: NDT (\%) = $\mathrm{dCNF}+\mathrm{dPB}+(\mathrm{dEE} \times 2,25)+\mathrm{dFDN}$, em que "d” representa a digestibilidade aparente dos diferentes componentes. Para conversão dos valores de NDT para energia metabolizável (EM) e energia digestível (ED) foram utilizadas as equações descritas a seguir, sugeridas pelo NRC (2001):

$\mathrm{EM}(\mathrm{Mcal} / \mathrm{kg})=1,01 \times \mathrm{ED}(\mathrm{Mcal} / \mathrm{kg})-0,45 ; \mathrm{ED}$ $(\mathrm{Mcal} / \mathrm{kg})=0,04409 \times \mathrm{NDT}(\%)$

As exigências líquidas de energia para mantença (ELm), foram estimadas como $71,22 \mathrm{kcal} / \mathrm{kg} \mathrm{PV}^{0,75} \mathrm{e}$, considerando a eficiência de utilização de 0,691, foi estimada a energia metabolizável para mantença como 103,07 kcal/kg PV 0,75 (Luo et al., 2004). A eficiência líquida de utilização da energia metabolizável consumida para produção de leite foi calculada através do consumo de energia metabolizável e da produção de leite, pela equação: Eficiência (ELp/CEMp-m), em que ELp é a energia liquida utilizada para produção de leite e CEMp-m é o consumo de energia metabolizável menos o consumo de energia metabolizável para mantença. A eficiência bruta da utilização da energia metabolizável para lactação foi calculada do consumo de energia líquida para mantença (CELm), segundo Luo et al. (2004) pela equação: Eficiência bruta [(CELm + Elp)/CEM]. O valor de energia líquida do leite foi calculado a partir dos dados sugeridos para vacas leiteiras (NRC, 2001), pela equação:

$\mathrm{EL}(\mathrm{Mcal} / \mathrm{kg})=0,0929 \times \mathrm{G}(\%)+0,0547 \times \mathrm{PB}(\%)+0,0395 \times$ Lac (\%), em que G, PB e Lac são, respectivamente, conteúdo de gordura, proteína bruta e lactose do leite.

Os dados submetidos à análise de variância foram desdobrados quanto ao efeito de tratamento nos componentes de regressões polinomiais, sendo que o nível de fibra em detergente neutro oriunda da forragem constituise na variável independente.

Os dados obtidos foram analisados por meio do programa computacional Statistical Analysis System (SAS, Institute Inc., 1999). A análise dos dados foi feita utilizando o procedimento GLM e os efeitos dos tratamentos, avaliados a 5\% de probabilidade, utilizando-se o teste F.

\section{Resultados e Discussão}

Com a variação nos teores de fibra em detergente neutro oriunda da forragem (FDNf) nas dietas de cabras em lactação, foram observados (Tabela 3) efeitos quadráticos nos consumos de matéria seca ( $\mathrm{kg} / \mathrm{dia}$, \%PV e g/ $/ \mathrm{kg}^{0,75}$ ), de matéria orgânica de proteína bruta, de extrato etéreo, expressos em kg/dia, e de energia líquida em Mcal/dia. Os consumos de fibra em detergente neutro, expressos em kg/dia e \%PV, apresentaram comportamento linear crescente com o aumento dos níveis de fibra oriunda da forragem das rações. De modo contrário o consumo de nutrientes digestíveis totais decresceu de maneira linear com o aumento dos níveis de fibra em detergente neutro oriunda da forragem.

Com base no exposto, pode-se enfatizar que o maior consumo de matéria seca e de energia líquida, ocorreu com animais que receberam dietas com 28 \% de FDNf,

Tabela 3 - Consumo de matéria seca e nutrientes por cabras em lactação alimentadas com dietas com diferentes níveis de fibra em detergente neutro oriunda da forragem

\begin{tabular}{|c|c|c|c|}
\hline & Equação estimada & $\mathrm{R}^{2}$ & CV (\%) \\
\hline Matéria seca (kg/dia) & $Y=0,3043+0,0647 x-0,0011 x^{2 *}$ & 0,82 & 8,57 \\
\hline Matéria seca (kg/kgPV) & $\mathrm{Y}=1,5642+0,1022 \mathrm{x}-0,0018 \mathrm{x}^{2 * *}$ & 0,86 & 6,01 \\
\hline Matéria seca $\left(\mathrm{g} / \mathrm{kg}^{0,75}\right)$ & $\mathrm{Y}=34,8619+2,8944 \mathrm{x}-0,0516 \mathrm{x}^{2 * *}$ & 0,85 & 6,19 \\
\hline Matéria orgânica (kg/dia) & $Y=0,065+0,0154 x-0,00026 x^{2 * *}$ & 0,83 & 9,48 \\
\hline Proteína bruta (kg/dia) & $Y=22,7036+1,1122 x-0,02950 x^{2 *}$ & 0,96 & 13,40 \\
\hline Extrato etéreo(g/dia) & $\mathrm{Y}=0,3428+0,0573 \mathrm{x}-0,0010 \mathrm{x}^{2^{*}}$ & 0,83 & 8,90 \\
\hline Fibra em detergente neutro (kg/dia) & $Y=0,1579+0,0078 x^{* * *}$ & 0,87 & 6,89 \\
\hline Fibra em detergente neutro (kg/kgPV) & $Y=0,6228+0,0125 x^{* * *}$ & 0,91 & 6,49 \\
\hline Carboidratos não-fibrosos (kg/dia) & $Y=0,7454-0,01271 x^{* *}$ & 0,80 & 26,60 \\
\hline Nutrientes digestíveis totais $3 \mathrm{x}(\mathrm{kg} / \mathrm{dia})$ & $\mathrm{Y}=1,1863-0,0078 \mathrm{x}^{*}$ & 0,71 & 9,34 \\
\hline Energia líquida $_{3 \mathrm{x}}$ (Mcal/dia) & $Y=0,7261+0,2063 x-0,0037 x^{2 * *}$ & 0,93 & 10,57 \\
\hline
\end{tabular}

* $\mathrm{P}<0,05 ; * * \mathrm{P}<0,01 ; * * * \mathrm{P}<0,0001$ 
sendo o ponto de inflexão de $27,27 \%$, uma vez que as ações dos controles físicos e fisiológicos são semelhantes e há maximização dos consumos de MS e dos nutrientes (Figura 1).

O consumo crescente de FDN observado, nas diversas formas em que foi expresso, pode ser atribuído ao aumento substancial nos níveis deste nutriente na dieta, em função da diminuição de concentrado nas rações, quando da variação do nível de FDNf, que aumentaram linearmente com a inclusão de volumoso na dieta. Carvalho et al. (2006) trabalhando com cabras em lactação e Resende et al. (2001), trabalhando com bovinos, encontraram resultados similares quando utilizaram dietas com diferentes níveis de FDN na dieta, sugerindo que houve uma acomodação da fibra no rúmen, e não uma repleção ruminal. Entretanto, Branco et al. (2010), trabalhando com cabras de mesmo potencial genético dos animais deste experimento, observaram repleção física do consumo, sendo que os consumos médios observados foram de $0,71 \mathrm{~kg} /$ dia de FDN e 1,24\% do peso vivo, sugerindo repleção do trato digestório e corroborando com Mertens (1994), o qual enfatiza que os animais consomem até atingir sua capacidade física.

Segundo Van Soest (1982) a natureza quadrática entre o consumo de matéria seca e a concentração de energia da dieta pode ser vista como indicativo de que há um ponto de transição entre os mecanismos físicos e fisiológicos que controlam a ingestão. Neste ponto, observa-se máximo consumo de matéria seca pelo animal. Esperar-se-ia, portanto, que o consumo de FDN fosse constante até, aproximadamente, o ponto de máximo consumo de matéria seca, que neste estudo ocorreu com o valor estimado de $28 \%$ de FDNf na ração. Contudo, o consumo de FDN aumentou linearmente com o aumento dos níveis de FDNf na dieta, podendo-se então presumir que a FDN não foi um bom indicativo de controle da ingestão voluntária no presente estudo.

Os valores de consumo observados, neste experimento, apresentaram uma menor magnitude, quando comparado com valores observados anteriormente com animais do mesmo rebanho (Branco et al., 2010; Bomfim, 2003; Carvalho et al., 2006). Este fato provavelmente deve-se à qualidade da forragem utilizada. Van Soest (1965) sugere que o conteúdo de fibra do alimento limita a ingestão quando as proporções desses constituintes aumentam na dieta, tornando assim aumentos na ingestão impossibilitados pelo volume ocupado pela massa fibrosa.

A fibra é caracterizada por apresentar lenta taxa de degradação no rúmen, ou mesmo, indigestibilidade. Como os componentes químicos da fibra fazem parte da parede celular das plantas, o tempo necessário para reduzir o tamanho destas estruturas é dependente da ação física da mastigação. Assim, na maioria das vezes a fibra apresenta uma reduzida taxa de trânsito, aumentando a quantidade de resíduos não digeridos que permanecem no rúmen, levando ao efeito de repleção (Rodrigues, 2004). A conseqüência disto é que alimentos que apresentam alta concentração de FDN, como o volumoso utilizado neste experimento, afetam o consumo com reflexos negativos na resposta animal.

Tem sido demonstrado que a fibra apresenta razão inversa com a disponibilidade de energia (Mertens, 1994). A relação entre o consumo de matéria seca e o conteúdo de FDN da ração apresenta natureza quadrática, o que foi observado neste experimento, sendo o ponto de inflexão o momento onde as ações do controle físico e fisiológico são semelhantes. A concentração de fibra na dieta, no ponto de inflexão, informa a quantidade máxima possível de forrageira para que o consumo de energia pelo animal seja maximizado.

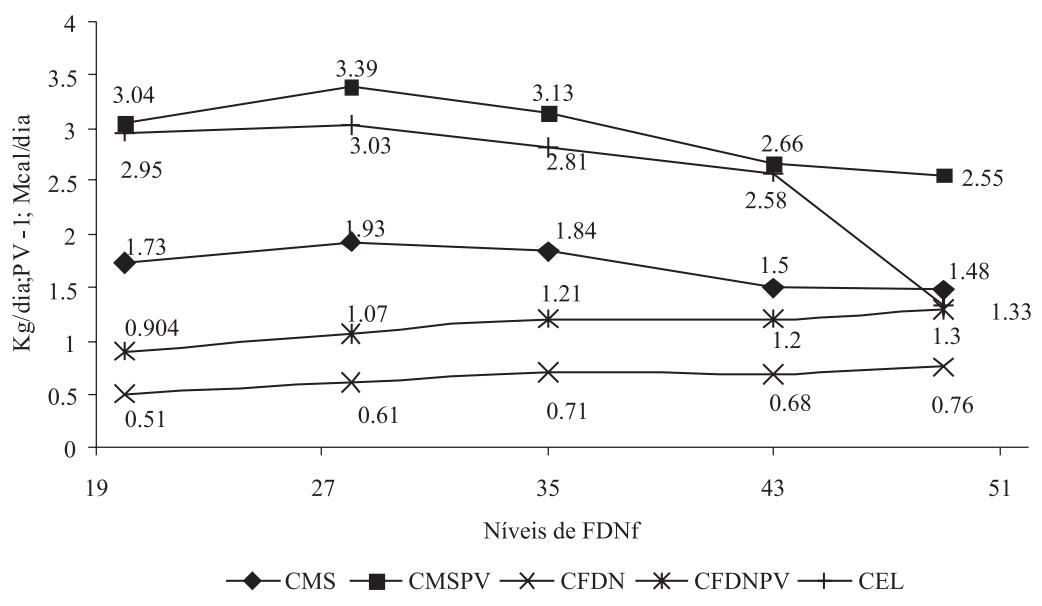

Figura 1 - Consumo de matéria seca, fibra em detergente neutro e energia líquida em cabras em lactação alimentadas com dietas com diferentes níveis de fibra oriunda da forragem. 
Mertens (1983) sugeriu que uma dieta apresentando 35\% de FDN seria capaz de estimular o máximo consumo de MS e fibra para vacas em lactação produzindo entre 25 a 30 litros de leite. Maiores concentrações de FDN limitariam o consumo devido aos efeitos da repleção no rúmen-retículo, enquanto que o consumo de dietas com menor concentração de FDN seria limitada ao atingir a exigência em energia do animal. As recomendações atuais do NRC (2001), sugerem o mínimo de 25 a 33\% de FDN na dieta, dependendo da proporção de FDN que é oriunda da forragem.

O valor médio de 1,25\% do peso do animal foi sugerido por Mertens (1992), para expressar a ótima ingestão de FDN na ração de animais em lactação. Esta recomendação é sugerida com base no princípio de que animais ruminantes teriam um consumo de fibra constante, após atingir o limite físico do rúmen. Atualmente, não existem dados suficientes sobre recomendações de níveis ótimos de fibra para a espécie caprina.

Carvalho et al. (2006) avaliou o efeito de dietas com diferentes teores de fibra sobre o consumo e a produção de leite de cabras, a fim de estabelecer limites máximos e mínimos recomendáveis nas rações. Nesse estudo foram testadas cinco dietas constituídas por diferentes teores de FDN proveniente da forragem, sendo os teores de FDNf utilizados de 20, 27, 34, 41 e 48\% da MS. O feno de capimtifton foi a base forrageira, considerado como de excelente qualidade, com valores de FDN de 69\% e 16\% em PB. Esse autor verificou efeito linear decrescente no consumo de MS, e efeito linear crescente no consumo de FDN, variando de 1,06 a $1,94 \%$ do PV, demonstrando que as cabras apresentaram capacidade de acomodar quantidades crescentes de fibra no rúmen, não sendo observado valor limite de ingestão de FDN pelos animais nas condições que foi conduzido este estudo. Este fato provavelmente deveu-se a melhor qualidade da forragem e ao menor conteúdo de parede celular. Ao analisar a eficiência com a qual a energia metabolizável da ração foi utilizada para produção de leite, verificou-se resposta crescente até teores de 35,4\% de FDNf, onde foi atingido um platô. Com base na produção de leite, no consumo de matéria seca, de fibra e da energia, foi sugerido teores de 35\% de FDNf, como sendo a concentração onde se obteria a melhor eficiência no uso de forrageiras em rações de cabras leiteiras, com produção semelhante aos animais usados neste estudo.

As análises de regressão dos coeficientes de digestibilidade aparente da MS, da matéria orgânica e dos carboidratos não-fibrosos em função do teor de FDNf na dieta revelaram efeito linear decrescente (Tabela 4). Houve, porém, efeito linear crescente no coeficiente de digestibilidade aparente da PB e efeito quadrático do coeficiente de digestibilidade aparente do EE. Todavia, a digestibilidade da FDN não foi afetada com o aumento dos níveis de FDNf nas rações (Figura 2).

O coeficiente de digestibilidade da proteína bruta apresentou efeito linear crescente, quando da inclusão de maiores níveis de FDNf nas rações, o que pode ser explicado pelo aumento de digestibilidade ruminal da proteína, verificado por Branco et al. (2010) ao avaliarem as mesmas dietas em animais fistulados. Comportamento este diferente dos relatados na literatura (Branco et al., 2010; Carvalho et al., 2006; Resende et al., 2001; Santini et al., 1992), que com o incremento nos teores em FDN ocorre aumento relativo nas perdas endógenas.

O efeito linear decrescente dos coeficientes de digestibilidade aparente da matéria seca e da matéria orgânica, com o aumento nos teores de FDNf, foi relatado de forma similar para matéria seca e orgânica por Carvalho (2002) e por Santini et al. (1992), os quais testaram teores crescentes de FDN na dieta de cabras Alpinas em lactação, por Bürguer et al. (2000), Carvalho (1996), Araújo et al.(1998) e Berchielli et al. (1996), que avaliaram diferentes níveis de FDN nas rações de bovinos. Segundo Rode et al. (1985), à medida que aumenta a fração volumosa, diminui a digestibilidade da matéria seca, provavelmente em virtude do aumento de carboidratos estruturais e diminuição no teor de carboidratos não-estruturais.

De maneira semelhante ao que foi obtido neste experimento, Branco et al. (2010) não encontraram efeito do teor de FDNf sobre o coeficiente de digestibilidade da FDN, sendo que os valores médios observados neste experimento,

Tabela 4 - Digestibilidade aparente da matéria seca e dos nutrientes em função dos teores de FDNf (\%) da dieta

\begin{tabular}{lccc}
\hline Variável & Equação estimada & $\mathrm{R}^{2}$ & $\mathrm{CV}(\%)$ \\
\hline Matéria seca (\%) & $\mathrm{Y}=85,7783-0,4014 \mathrm{x}^{* * *}$ & 0,90 & 4,54 \\
Matéria orgânica (\%) & $\mathrm{Y}=86,5455-0,4044 \mathrm{x}^{* * *}$ & 0,90 & 4,46 \\
Proteína bruta (\%) & $\mathrm{Y}=70,8659+0,3801 \mathrm{x}^{* *}$ & 0,89 & 4,81 \\
Extrato etéreo (\%) & $\mathrm{Y}=56,0142+2,4623 \mathrm{x}-0,0449 \mathrm{x}^{2 * *}$ & 0,96 & 4,66 \\
Fibra em detergente neutro (\%) & $\mathrm{Y}=55,68$ & - & 0,93 \\
Carboidratos não-fibrosos (\%) & $\mathrm{Y}=94,2605-0,3999 \mathrm{x}^{* *}$ & 8,74 \\
\hline
\end{tabular}

${ }^{*} \mathrm{P}<0,05 ;{ }^{* *} \mathrm{P}<0,01 ;{ }^{* * *} \mathrm{P}<0,0001$ 
55,68\%, foram menores aos relatados pela referida autora, que observou valores próximos de 59,26\% e inferiores também aos relatado por Carvalho et al. (2006), que obtiveram valores médios de digestibilidade da FDN de 61,52\%.

Os valores obtidos para digestibilidade dos carboidratos não-fibrosos, foram similares aos divulgados por Bomfim (2003) e por Valadares Filho et al. (1987). Segundo Valadares Filho et al. (1987), carboidratos solúveis em detergente neutro possuem digestibilidade aparente próximos a $90 \%$ e carboidratos estruturais próximos de $50 \%$, o que reflete na maior digestão da matéria seca nas rações com menores teores de carboidratos estruturais (menor teor de FDN).

A produção de leite foi afetada pela variação nos teores de FDNf (Tabela 5). Houve efeito quadrático para produção de leite e leite corrigido para $4 \%$ de gordura, com o aumento nos teores de FDNf, até 28\% (Figura 3). Os maiores consumos de matéria seca e de energia líquida (Tabela 3; Figura 1), provavelmente foram as variáveis envolvidas na resposta em produção das cabras leiteiras. As eficiências de utilização de energia (líquida e bruta) não foram influenciadas pelas dietas.

Os constituintes do leite (gordura, proteína e lactose) não foram alterados pelo aumento nos teores de FDNf nas rações (Tabela 5). O teor de gordura do leite apresentou valor médio de 3,32 \%, nesse sentido, é importante salientar que o efeito da efetividade física da fibra dietética é preponderante sobre o percentual de gordura do leite. De acordo com Lammers et al. (1996), reduções nos teores de fibra nas dietas levam à diminuição no tempo gasto de mastigação (comendo e ruminando) e, conseqüentemente, à redução do $\mathrm{pH}$ ruminal, em função de menor fluxo de saliva para o rúmen, reduzindo o fluxo de substâncias tamponantes.

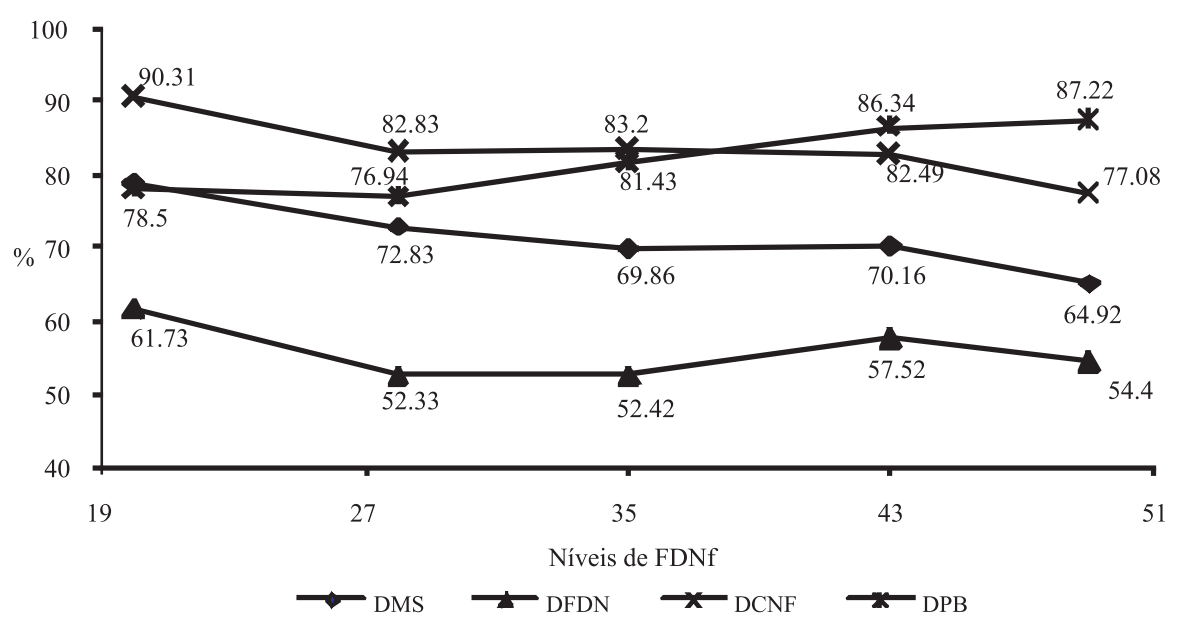

Figura 2 - Coeficientes de digestibilidade da matéria seca, da fibra em detergente neutro, dos carboidratos não-fibrosos e da proteína bruta em cabras em lactação alimentadas com dietas com diferentes níveis de fibra oriunda da forragem.

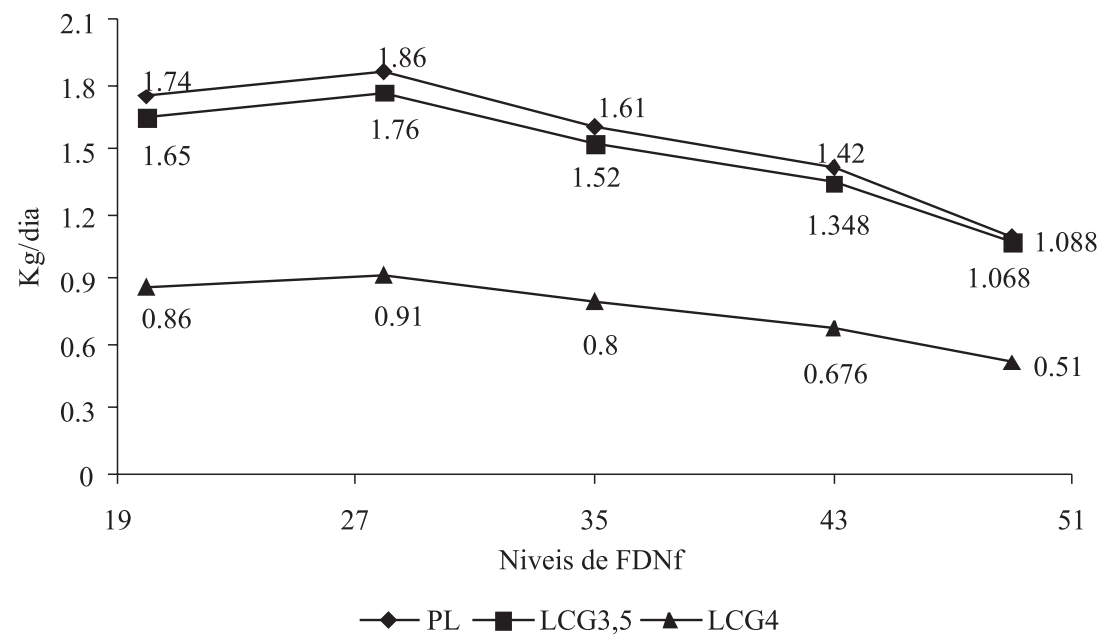

Figura 3 - Produção de leite total (PL) e produção corrigida para 3,5\% (LCG 3,5) e 4\% de gordura (LCG4) em cabras em lactação alimentadas com dietas com diferentes níveis de fibra oriunda da forragem. 
Tabela 5 - Produção e composição de leite de cabras em lactação alimentadas com dietas com diferentes níveis de fibra oriunda da forragem

\begin{tabular}{|c|c|c|c|}
\hline Variável & Equação estimada & $r^{2}$ & CV (\%) \\
\hline Produção de leite (kg.dia-1) & $Y=0,077+0,067 x-0,0013 x^{2^{*}}$ & 0,98 & 14,79 \\
\hline LCG 3,5\% (kg.dia-1 $)$ & $\mathrm{Y}=1,38-0,021 \mathrm{x}^{* *}$ & 0,82 & 19,05 \\
\hline LCG 4\% (kg.dia $\left.{ }^{-1}\right)$ & $Y=0,0098+0,00328 x-0,00067 x^{2 *}$ & 0,98 & 15,30 \\
\hline LCST (kg.dia $\left.{ }^{-1}\right)$ & $Y=364,97-6,29 x^{* *}$ & 0,84 & 18,04 \\
\hline Gordura (\%) & $Y=3,32$ & - & 14,56 \\
\hline Proteína (\%) & $\mathrm{Y}=2,97$ & - & 7,93 \\
\hline Lactose $(\%)$ & $\mathrm{Y}=4,07$ & - & 6,76 \\
\hline Proteína (kg.dia $\left.{ }^{-1}\right)$ & $\mathrm{Y}=0,053-0,00072 \mathrm{x}^{* *}$ & 0,85 & 18,48 \\
\hline Gordura (kg.dia $\left.{ }^{-1}\right)$ & $\mathrm{Y}=0,048-0,00077 \mathrm{X}^{* *}$ & 0,89 & 25,59 \\
\hline Lactose $\left(\mathrm{kg} \cdot \mathrm{dia}^{-1}\right)$ & $\mathrm{Y}=0,0624$ & - & 35,62 \\
\hline $\mathrm{Kl}$ & $Y=0,41$ & - & 33,25 \\
\hline Kmpo & $Y=0,65$ & - & 28,25 \\
\hline
\end{tabular}

LCG 3,5\% = produção de leite corrigida para 3,5\% de gordura; LCG 4\% = produção de leite corrigida para 4\% de gordura; LCST = produção de leite corrigida para sólidos totais; $\mathrm{Kl}$ = eficiência de utilização líquida da energia metabolizável consumida; Kmpo = eficiência de utilização bruta da energia metabolizável consumida.

${ }^{*} \mathrm{P}<0,05 ;{ }^{* *} \mathrm{P}<0,01 ;{ }^{* * *} \mathrm{P}<0,0001$

Isso proporciona um ambiente ruminal desfavorável para o crescimento de microrganismos celulolíticos, o que leva a redução da relação acetato:propionato e, como consequência, à redução do teor de gordura do leite. Como o teor de gordura não diferiu entre os tratamentos acredita-se que a redução no teor de fibra dietética não comprometeu a efetividade.

O efeito do teor e da qualidade da fibra da forragem sobre a produção de leite ocorre de maneira direta. Com o aumento da concentração de FDN da forragem, ocorre diminuição no conteúdo de energia, podendo determinar restrição na ingestão de MS, seja pela diminuição da taxa de digestão ruminal, pela redução da taxa de passagem da fibra ou pela mudança na regulação de consumo, afetando diretamente a partição de nutrientes para a produção. Stensing \& Robinson (1997), trabalhando com teores diferentes de FDN nas rações para vacas em lactação observaram que, com o aumento nos teores de FDN, houve diminuição na produção de leite. Estes resultados foram semelhantes aos observados por Dado \& Allen (1995), que relataram comprometimento na produção de leite com a inclusão de maiores teores de FDN nas rações, independente do potencial produtivo dos animais.

Segundo Mertens (1995), o sistema de ingestão FDNenergia indica que as diferenças entre as forragens podem ter pouco impacto na ingestão e produção de leite, quando as rações são formuladas para conterem a mesma concentração de FDN. Esse sistema implica que diferenças na qualidade da forragem podem ser compensadas pelas mudanças na relação volumoso: concentrado. Embora a FDN possa diferir na taxa e extensão de digestão, o sistema FDN-energia prediz que esses efeitos são insignificantes em relação à disponibilidade de carboidratos fibrosos e não-fibrosos que está presente na ração. Em efeito, o sistema substitui a fibra da forragem com carboidratos não-fibrosos do concentrado para manter uma ingestão constante de FDN quando a qualidade da forragem varia. Porém, é sabido que fibras de diferentes fontes e com diferenças em maturidade poderão provocar reduções de magnitudes variadas no consumo e digestibilidade. A qualidade da forragem pode representar um importante fator diferenciador na resposta animal, quando estes são alimentados com rações contendo a mesma concentração de fibra de origem da forragem, mas com qualidade variada.

Branco et al. (2010), trabalhando com os teores semelhantes de FDNf deste experimento e cabras do mesmo plantel, observaram produções mais elevadas, do que as observadas no presente ensaio, utilizando animais com potencial de leite similar, variando de 2,75 a 1,89 kg de leite, com utilização de forragem de qualidade superior a utilizada neste experimento, onde a maior produção de leite observada neste experimento $(1,86 \mathrm{~kg} / \mathrm{dia})$ foi inferior a produção observada $(1,89 \mathrm{~kg} /$ dia) obtida com o emprego do maior nível de FDNf.

Com o aumento nos teores de FDNf nas rações experimentais, foi observado efeito quadrático no tempo despendido com ruminação, com mastigação total (alimentação e ruminação) e em ócio (Tabela 6). O tempo gasto com alimentação, em pé ou deitado não foram influenciados pelo aumento nos teores de FDNf nas rações experimentais, apresentando valores médios de 262,00; 555,60 e 884,40 minutos/dia, respectivamente (Figura 4). O tempo gasto com mastigação foi maior, devido ao aumento do tempo despendido com ruminação em função dos teores em FDN na ração, mais do que com o tempo em alimentação.

O efeito quadrático teor de FDNf nas rações sobre o tempo despendido com ruminação está de acordo com Van Soest (1994), o qual afirma que o tempo ruminando é proporcional ao teor de fibra dos alimentos consumidos. 
Tabela 6 - Comportamento ingestivo das cabras e tempo de permanência em pé ou deitadas

\begin{tabular}{|c|c|c|c|}
\hline Variável & Equação estimada & $r^{2}$ & CV (\%) \\
\hline 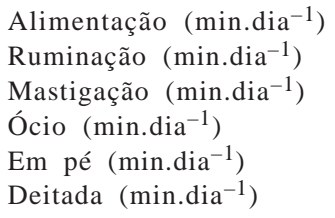 & $\begin{array}{l}Y=262,00 \\
Y=-241,03+39,63 x-0,50 x^{2 * * *} \\
Y=-380,46+58,17 x-0,76 x^{2 * *} \\
Y=1820,46-58,17 x-0,76 x^{2 * * *} \\
Y=555,60 \\
Y=884,40\end{array}$ & $\begin{array}{l}- \\
0,93 \\
0,95 \\
0,95 \\
- \\
-\end{array}$ & $\begin{array}{c}21,97 \\
9,85 \\
8,80 \\
8,78 \\
13,45 \\
8,45\end{array}$ \\
\hline $\begin{array}{l}\text { Alimentação } \\
\text { Min (kg.MS) } \\
\text { Min (kg.FDN) } \\
\text { Min (g MS. }\left(\mathrm{kg}^{0,75}\right)^{-1} \\
\left.\text { Min (g FDN.(kg }{ }^{0,75}\right)^{-1}\end{array}$ & $\begin{array}{l}Y=101,92+1,44 x^{*} \\
Y=479,80-3,43 x^{*} \\
Y=1,21+0,038 x^{*} \\
Y=7,72\end{array}$ & $\begin{array}{l}0,67 \\
0,67 \\
0,80 \\
-\end{array}$ & $\begin{array}{l}23,29 \\
20,54 \\
22,56 \\
18,84\end{array}$ \\
\hline $\begin{array}{l}\text { Ruminação } \\
\text { Min (kg.MS) })^{-1} \\
\text { Min (kg.FDN)-1 } \\
\left.\text { Min (g MS.(kg }{ }^{0,75}\right)^{-1} \\
\left.\text { Min (g FDN.(kg }{ }^{0,75}\right)^{-1}\end{array}$ & $\begin{array}{l}\mathrm{Y}=223,69+5,14 \mathrm{x}^{* * *} \\
\mathrm{Y}=304,77+38,27 \mathrm{x}-0,55 \mathrm{x}^{2 * *} \\
\mathrm{Y}=2,83+0,12 \mathrm{x}^{* * *} \\
\mathrm{Y}=1,16+0,88 \mathrm{x}-0,0122 \mathrm{x}^{2 * *}\end{array}$ & $\begin{array}{l}0,97 \\
0,81 \\
0,97 \\
0,78\end{array}$ & $\begin{array}{c}11,66 \\
10,52 \\
12,23 \\
9,13\end{array}$ \\
\hline
\end{tabular}

${ }^{*} \mathrm{P}<0,05 ;{ }^{* *} \mathrm{P}<0,01,{ }^{* * *} \mathrm{P}<0,0001$

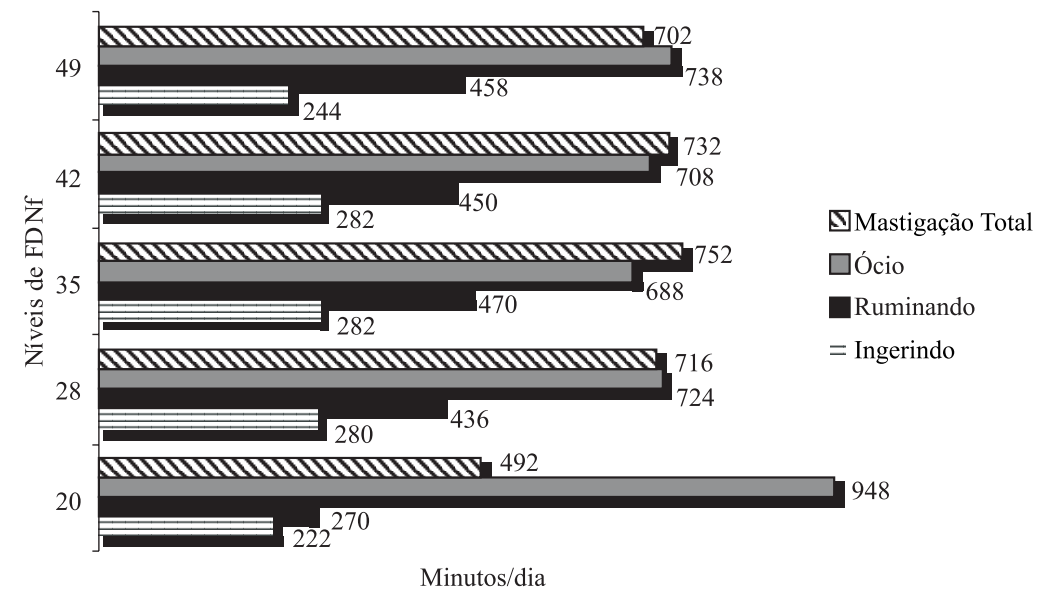

Figura 4 - Comportamento ingestivo de cabras em lactação alimentadas com dietas contendo diferentes níveis de fibra oriunda da forragem.

Concorda também com os relatos de Church (1988) de que forragens com alto teor de FDN necessitam de maior período de ruminação, refletindo em maior necessidade do processamento da fibra da dieta para passar através do trato digestório dos ruminantes. $\mathrm{O}$ animal gastou mais tempo para consumir a mesma quantidade de matéria seca quando houve aumento na concentração de fibra da dieta. De forma inversa, observou-se redução no tempo necessário para o consumo quando este é expresso em kg de FDN consumido.

Com a elevação nos teores de FDNf nas rações, foi observado efeito linear crescente no tempo em alimentação, quando expresso em kg.MS ${ }^{-1}$, e em g.MS $\left(\mathrm{kg}^{0,75}\right)^{-1}$ e um efeito linear decrescente no tempo com alimentação, quando expresso em $\mathrm{kg} \mathrm{FDN}^{-1}$. Quando foram avaliados os tempos em ruminação, foi observado efeito linear crescente, quando este foi expresso em kg de MS e em g de MS por unidade de tamanho metabólico e efeito quadrático quando o tempo de ruminação foi expresso em $\mathrm{kg}$ de FDN e em $\mathrm{kg}$ de FDN por unidade de tamanho metabólico.

Segundo Miranda et al. (1999), o tempo gasto em alimentação, ruminação e mastigação por unidade de consumo de matéria seca e de fibra em detergente neutro é maior com a adição de fibra na dieta e que o aumento da atividade mastigatória pode proporcionar incremento da digestão ruminal e passagem.

O aumento no tempo gasto com a ruminação e mastigação total, ao se elevar a concentração de FDNf, pode ser considerado uma consequência da proporção de forragem da dieta. Segundo Nelson \& Satter (1992) o aumento da maturidade das forragens resultam em vários efeitos em animais em lactação como: maior tempo gasto em ruminação, maior tempo em atividades de mastigação total, maiores 
pesos e volumes de conteúdo ruminal e maior efeito de repleção ruminal.

Os valores observados neste experimento foram similares aos relatados por Carvalho et al. (2006) e por Santini et al. (1992), os quais trabalharam com diferentes teores de FDN nas rações para cabras em lactação e obtiveram médias de 296,73; 396,12; 714 minutos/dia para alimentação, ruminação e ócio, respectivamente.

O uso de forragem com maturidade avançada é limitante caso seja necessário alimentar cabras com grande capacidade de produção leiteira, isto porque a participação da forrageira em dietas com teores reduzidos de fibra, para garantir alto consumo de energia disponível, deverá ser pequena. Existe, no entanto, uma dificuldade do animal lidar fisiologicamente com os teores mais elevados de concentrados na ração, uma vez que a estabilidade do ambiente ruminal ficará prejudicada, o tempo gasto em ruminação será reduzido, contribuindo com menor tamponamento do rúmen levando a maior variação do $\mathrm{pH}$, podendo provocar uma queda no consumo, o que não é desejável. A observação de acidose é comum nos casos quando são usados teores elevados de concentrados nas dietas dos animais ruminantes. A própria redução no consumo pelos animais pode ser reflexo de uma acidose subclínica, ou de outras complicações metabólicas relacionadas ao uso de concentrados em demasia. Por outro lado, o uso de teores mais elevados de fibra na dieta, proveniente de forrageiras com maturidade avançada, ocasionará redução no consumo pela limitação física e talvez não se consiga atender as exigências de animais com alto potencial genético, comprometendo assim a produtividade animal.

\section{Conclusões}

Em níveis a partir de 28\%, o aumento nos teores de fibra em detergente neutro oriunda de forragem considerada de maturidade avançada implica redução no consumo de matéria seca, matéria orgânica, proteína bruta, extrato etéreo e energia líquida, comprometendo a produção de leite. O uso de forragem com maturidade avançada na alimentação de cabras de alta produção leiteira tem limitações. Portanto, a participação da forrageira em dietas com baixos teores de fibra, para garantir alto consumo de energia disponível, deve ser pequena.

\section{Referências}

AGRICULTURAL FOOD RESEARCH COUNCIL - AFRC. Energy and protein requirements of ruminants. An advisory manual prepared by the AFRC Technical Committee on Responses to Nutrients. Compiled by G. Alderman. Wallingford: CAB International, 1993. 159p.
ARAÚJO, G.G.L.; COELHO DA SILVA, J.F.; VALADARES FILHO, S.C. et al. Consumo e digestibilidade total dos nutrientes de dietas contendo diferentes níveis de volumoso, em bezerros. Revista Brasileira de Zootecnia, v.27, n.2, p.345-354, 1998.

BERCHIELLI, T.T.; RODRIGUES, N.M.; OLIVEIRA, H.P. Efeito de diferentes relações volumoso:concentrado no consumo, digestibilidade aparente e partição da digestão de dieta de bovinos. Arquivo Brasileiro de Medicina Veterinária e Zootecnia, v.48, n.5, p.607-617, 1996.

BOMFIM, M.A.D. Carboidratos solúveis em detergente neutro em dietas de cabras leiteiras. 2003. 119f. Tese (Doutorado em Zootecnia) - Universidade Federal de Viçosa, Viçosa, MG.

BRANCO, R.H.; RODRIGUES, M.T.; RODRIGUES, C.A.F. et al. Efeito dos níveis de fibra em detergente neutro oriunda da forragem sobre a eficiência microbiana e os parâmetros digestivos em cabras leiteiras. Revista Brasileira de Zootecnia, v.39, n.2, p.372-381, 2010

BURGER; P.J.; PEREIRA, J.C.; COELHO DA SILVA, J.F. et al. Consumo e digestibilidade aparente total e parcial em bezerros holandeses alimentados com dietas contendo diferentes níveis de concentrado. Revista Brasileira de Zootecnia, v.29, n.1, p.206-214, 2000.

CARVALHO, A.U. Níveis de concentrado na dieta de zebuínos: consumo, digestibilidade e eficiência microbiana. 1996. 113f. Tese (Doutorado em Zootecnia) - Universidade Federal de Viçosa, Viçosa, MG

CARVALHO, S.; RODRIGUES, M.T.; BRANCO, R.H. et al. Consumo de nutrientes, produção e composição do leite de cabras da raça Alpina alimentadas com dietas contendo diferentes teores de fibra. Revista Brasileira de Zootecnia, v.35, n.3, p.1154-1661, 2006.

CHURCH, D.C. El rumiante: fisiología digestiva y nutrición. Zaragoza: Acribia, 1988. 641p.

DADO, R.G.; ALLEN, M.S. Intake limitation, feeding behavior and rumen function of cows challenged with rumen fill from dietary fiber or inert bulk. Journal of dairy Science, v.78, n.1, p.118-133, 1995.

DULPHY, J.P.; REMOND, B.; THERIEZ, M. Ingestive behavior and related activities in ruminants. In: RUCKEBUSH, Y., THIVEND, P. (Eds.), Digestive physiology and metabolism in ruminants. Lancaster: MTP, 1980. p.103-122.

LAMMERS, B.P.; BUCKMASTER, D.R.; HEIRICHS, A.J. A simple method for the analysis of particle sizes of forage and total mixed rations. Journal of Dairy Science, v.79, n.5. p.922-928, 1996.

LICITRA, G.; HERNANDEZ, T.M.; Van SOEST, P.J. Standardization of procedures for nitrogen fractionation of ruminants feeds. Animal Feed Science and Technology, v.57, p.347-358, 1996.

LUO, J.; GOETSCH, A.L.; NSAHLAI, I.V. et al. Maintenance energy requirements of goats: predictions based on observations of heat and recovered energy. Small Ruminant Research, v.53. p.221-230, 2004.

MERTENS, D.R. Creating a system for meeting the fiber requirements of dairy cows. Journal of Dairy Science, v.80, p.1463-1481, 1997.

MERTENS, D.R. Formulating dairy rations: using fiber and carbohydrate analyses to formulate dairy rations. In: INFORMATION CONFERENCE WITH DAIRY AND FORAGE INDUSTRIES, Madison, 1996. Proceedings... Madison: U.S. Dairy Forage and Research Center, 1996. p.81-92.

MERTENS, D.R. Comparing forage sources in dairy rations containing similar neutral detergent fiber concentrations. [s.l.]: U.S. Dairy Forage Research Center, 1995. p.87-90. (Research Summaries).

MERTENS, D.R. Regulation of forage intake. In: FAHEY JUNIOR, G.C.; COLlins, M.; MERTENS, D.R. et al. (Eds.) Forage quality, evaluation, and utilization. Madison: American Society of Agronomy, Crop Science Society American, and Soil Science Society of America, 1994. p.450-493. 
MERTENS, D.R. Nonstructural and structural carbohydrates. In: Van HORN, H.H.; WILCOX, C.J. (Eds.) Large dairy herd management. Champaign: American Dairy Science Association, 1992. p.60-69.

MERTENS, D.R. Using neutral detergent fiber to formulate dairy rations and estimate the net energy content of forages. Itha ca: Cornell University, 1983. p.60-69.

MIRANDA, L.F.; QUEIROZ, A.C.; VALADARES FILHO, S.C. et al. Comportamento ingestivo de novilhas leiteiras alimentadas com dietas à base de cana-de-açúcar. Revista Brasileira de Zootecnia, v.28, n.3, p.614-620, 1999.

NATIONAL RESEARCH COUNCIL. Nutrient requirements of dairy cattle. 7.ed. Washington, D.C.: National Academic Press, 2001. 387 p.

NELSON, W.F.; SATTER, L.D. Impact of alfalfa maturity and preservation method on milk production by cows in early lactation. Journal of Dairy Science, v.75, n.6, p.1562-1570. 1992.

NUSSIO, L.G.; LIMA, M.L.M.; MATTO, W.R.S. Caracterização e importância da fibra na alimentação de ruminantes. In: SIMPÓSIO INTERNACIONAL SOBRE PRODUÇÃO DE BOVINOS LEITEIROS, Carambeí, 2000. Anais... Carambeí: Fundação ABC, 2000. (CD-ROM).

RESENDE, F.D.; QUEIROZ, A.C.; OLIVEIRA, J.V. et al. Bovinos mestiços alimentados com diferentes proporções de volumoso:concentrado. 2. Efeito sobre a ingestão de nutrientes. Revista Brasileira de Zootecnia, v.30, n.1, p.270-279, 2001.

RODE, L.M.; WEAKLEY, D.C.; SATTER, L.D. Effect of forage amount and particle size in diets of lactating dairy cows on site of digestion and microbial synthesis. Canadian Journal of Animal Science, v.65, n.1, p.101-11, 1985.
RODRIGUES, M.T. Alimentação de cabras leiteiras. In: ENDEC ENCONTRO NACIONAL PARA O DESENVOLVIMENTO DA ESPÉCIE CAPRINA, 8., 2004, Botucatu. Anais... Botucatu, 2004. p.121-154.

SANTINI, F.J.; LU, C.D.; POTCHOIBA, M.J. et al. Dietary fiber and milk yield, mastication, digestion, and rate of passage in goats fed alfalfa hay. Journal of Dairy Science, v.75. p.209-219, 1992.

SILVA, D.J.; QUEIROZ, A.C. Análise de alimentos (métodos químicos e biológicos). Viçosa, MG: UFV, 2002. 235p.

STENSING, T.; ROBINSON, P.H. Digestion and passage kinetics of forage fiber in dairy cows as affected by fiber-free concentrate in the diet. Journal of Dairy Science, v.80, n.7, p.1339-1352, 1997.

VALADARES FILHO, S.C.; SILVA, J.F.C.; LEAO, M.I. et al. Estudo comparativo da digestão da matéria seca e carboidratos em bovinos e bubalinos alimentados com diferentes rações Revista Brasileira de Zootecnia, v.16, n.2, p.120-130, 1987.

VAN SOEST, P.J. Nutritional ecology of the ruminant. 2.ed. Ithaca: Comstock, 1994. 476p.

VAN SOEST, P.J. Nutritional ecology of the ruminant. Corvalis: O\&B Books, 1982. 374p.

VAN SOEST, P.J. Symposium on factors influencing the voluntary intake in relation to chemical composition and digestibility. Journal of Animal Science, v.24, n.2, p.834-843, 1965.

VAN SOEST, P.J.; ROBERTSON, J.B.; LEWIS, B.A. Methods of dietary fiber, neutral detergent fiber, and nonstarch polysaccharides in relation to animal nutrition. Journal of Dairy Science, v.74, p.3583-3597, 1991.

WELCH, J.G. Rumination, particle size and passage from the rumen. Journal of Animal Science, v.54, n.4, p.885-895, 1982. 